3rd.-Having in vain attempted, on the evening of the 19 th September, to organize a corps of house-to-house visitors from the gentlemen then acting in Newcastle as assistants, and doing the double work of assistants and medical visitors. Having failed because these gentlemen could not apprehend the distinction between medical visitors engaged specially in house-to-house visitation, and medical assistants engaged in attendance upon the sick; and because their services as attendants on the sick could not possibly be dispensed with; and, further, because they would not undertake the very arduous service proposed to be exacted of the visitors; it was essential for the public safety that that which conld not possibly be obtained in Newcastle should be obtained elsewhere.

Application was accordingly made to London and other places for additional assistance. Among those who wcre sent to Newcastle on such application were two persons, one of whom I had never seen or heard of before. In a few days he was reported as practising homoopathically. Immediately on this information his services were dispensed with.

The second person $I$ had seen once in Whitechapel, while he was attending a depôt for medicines there.

As I had no control over the arrival of this person at Newcastle, which arrival I regretted much, I felt that all that could be done was to dispense with his services so soon as myself and colleague had sufficient cause for recommending his discharge. The opportunity was afforded, and we then promptly acted.

The statements of your correspondent, that I defended him, and that he is, or ever was, a personal friend, are unblushing and unmitigated untruths, on whatever authority they are made.

4th. - I take this opportunity of stating that no visitor ever received from me instructions to bring forward, or seek out, charges of neglect against any medical officer; on the contrary, the visitors were on this occasion,-as they invariably are on all occasions by the medical inspector who may direct their operations,-cautioned and instructed over and over again, that, while they were to be diligent in their business, they were never on any account to interfere with cases already under treatment. Any other conduct would, they were repeatedly informed, be highly detrimental to the public service, injurious to the canse they served, and be considered as disqualifying them for the service they were engaged in. They were, and are, always directed to be courteous, aiding and co-operating with, as far as possible, the local medical officers; and it forms no part of their duties, any more than it does that of any gentlemen, to act as spies on such occasions,-scandalseeking in reference to their professional brethren.

The cases reported by the person in question were cases of supposed discovery, not cases of neglected disease. His tes timony was not considered sufficiently valid, or capable of demonstrative proof, which all such must be. To avoid any source of error, therefore, his cases of reported cholera, \&c., were considered as under medical treatment-were erased from the returns, and he himself was removed from the staff.

Even, however, supposing that the cases entered as " discovered"-i.e., not under medical treatment-had received no medical treatment, it by no means follows that the medical officer had neglected the cases. He may never have known of such cases except in the death list.

It almost invariably follows that some persons are discovered to have died without receiving medical aid when the visitation first commences, but such cases should never occur except in the first week of the risitation. In Dundee, for example, one corpse was thus discovered on the first day of the visitation.

You, Sir, will consider how extremely difficult it must have been in the course of one or two days to procure a corps of persons who should be all qualified, all gentlemen, and all well disposed to perform their duty with diligence, trustworthiness, and a consciousness of the responsibility imposed upon them. $I$, at least, in this instance, experienced how difficult it was to procure such aid,--how trying was the task, and how rexations.

The task of organizing a corps of house-to-house visitors, instructing them in their duties, and carefully watching their operations, is of no easy character. The difficult $y$ is increased when the organization takes place for the first time during a period of great emergency, and when aid of any kind is by necessity grasped at. MIoreover, the appointment of such officers rests entirely with the local authorities, and it is only to proride that aid which they cannot obtain that the medical inspectors occasionally endeavour to procure the services of visitors.
Happily, with the two exceptions named, there is not, so far as I know, any valid reason to be dissatisfied with the services of the gentlemen who acted as house-to-house visitors. On the contrary, testimony can be borne to the efficient performance of their delicate and arduous duties. Many of them have distinguished themselves, have gained the affections of the people, and merited the grateful thanks of the community they served.

I have dwelt thus on the reference made to the visitors, because it is in my mind of great public moment that a right apprehension should prevail as to the nature of house visitation, and that the faults of two individuals, who improperly obtained appointments, should not be mixed up with the system itself

6th. - If the coroner, as alleged, suspended his office, with that, even if true, the Board of Health and its officers are certainly not immediately concerned.

7th. - As for matters personal to myself, the profession are not interested in them, and I decline to notice the language of the individual.

8th. - It is unnecessary for any officer of the board to notice the slander of "cooked accounts" supported by reference to newspaper paragraphs. My own reputation for careful inquiry and elimination of facts I believe to be sufficiently well established to place me beyond the reach of the individual who has so singularly exhibited himself in your columns; and I do not suppose that the reputation of Mr. Grainger, Dr. Lewis, or Mr. Lee, gentlemen of high honour and qualifications, and accustomed to careful and abstract inquiry, requires to be defended at my hands under such circumstances.

A confusion between Gateshead Union and Gateshead, and an error in reading or conveying a telegraphic return of deaths, is the source of the sweeping charge, which is moreover affixed to the wrong quarter.

9th.-Might there not, Mr. Editor, be something said as to what might be fairly due to gentlemen endeavouring to carry out, as government officers, the intentions of the Legislature and the law of the land in times of great emergency-when the greatest possible freedom from local jealonsies, prejudices, and contending interests is, as in Newcastle, essential to the well-being of thousands; and mioht it not possibly be inquired whether one or two isolated parties, instead of being justified in complaining, ought on the contrary not to be arraigned at the bar of professional opinion.

10th.-For myself, I have to thank the great body of the professional gentlemen in Newcrstle, with whom my official duties have brought me into communication, for their ready co-operation, as far as the overwhelming duties they were engaged in during the epidemic permitted them to co-operate with me. With their good opinion, and the numerous expressions of their regard, good feeling, and approbation which I have received, I leave in silence the conduct of your correspondent to receive at the hands of gentlemen the judgment which they shall think fit to pass upon it.

I have the honour to be, Sir,

Your obedient servant,

Hector Gavin, M.D., F.R.C.S. Edin., Medical Inspector, West India Colonies,

And Medical Superintending Inspector, General Board of Health. Dundee, Nor. 1853 ,

\section{THE LONDON HOSPITAL.}

ASSISTANT-SURGEONCY IN THE H.E.T.CO.'S SERVICE. To the Editor of THE LANCET.

SrR,- - Having this day seen letters in your two last journals relative to the surgical appointments in the East India Com: pany's Service, awarded to Messrs. Harris and Dale, in one of which the decision of my late teachers was impugned, I consider that it would be a dereliction of duty on my part were I not to state through the medium of your columns that it was not only perfectly satisfactory to myself, but, I believe I may add, to a large majority of my late fellow-students.

I am, Sir, yours respectfully,

Eastern Dispensary, Bath, Nov. 1853. ALFRED ADAMS MANTELd.

\section{A NEW MIODE OF OBTATNING THE APOTHECARIES LICENCE.}

To the Elitor of THe LANCET.

SIR,-Having observed in your number for the 29 th ult. the description of a "novel methor of obtaining a diploma," and having recently seen in a Scotch newspaper the account of a prosecution of a party for practising in Ayrshire with a diploma, 
doubtless obtained in some such novel mode as your correspondent describes, in which he had inserted his own name after effacing that of the rightful owner, I think some plan might be adopted for stopping such criminal proceedings, since the Ayrshire case shows that the relatives of deceased surgeons do not always act so honourably as the lady mentioned by your correspondent; and who knows but there are humdreds of people practising in the colonies, if not in the mother country, with worn-out diplomas! How would it do to make it a clause in the New Medical Reform Bill, that the different licensing Boards should be obliged to cause the diplomas of their licentiates to be returned at the death of the holders, in the same way as Government causes the relatives of those who die holding the honourable titles of C.B. \&c. to return the badges of these honours? If some such system were adopted, a very flagrant branch of quackery would be effectually extinguished.

Nov. 1853.

I am, Sir, your obedient servant,

Scotus.

\section{TH E C H O L R A.}

During the past week the disease has attacked persons in several fresh localities.

\section{November 10.}

DUNDEE, -Nov. 8,5 deaths.

Codpar Angus (N.B.)-Nov. 5 to 9,1 death.

Soham (Cambridgeshire).--Nov. 9, 2 deaths; diarrhcea, 1 death.

Merton And Mrtcham.-There have been four attacks of cholera in this district, and three deaths. The fatal cases have run their course with extraordinary rapidity. In two instances death occurred within ten hours from the attack, the patients having been previously in a state of apparent health. In the third instance the man had been slightly ailing for some time, but he was in his usual health the evening before the attack, and slept quietly during the night. About eight o'clock A.M. he was rapidly purged five times; he then went to work, but remained only a short time, and returned home and took some brandy; he again ventured to go out, but was constrained to come back, and forthwith the alarming symptoms set in, and proved fatal at 11 P.M.

The MeTropolis. - The returns from the divisions D, K, M, $P$, and $S$ of the Metropolitan Police for the 9 th inst. give 18 cases of cholera and 10 deaths. In one house in Devonshireplace, Marylebone, three cases occurred, of which two have proved fatal, and the remaining patient is dangerously ill. With reference to a death that took place at No. 9, Albion. place, Bermondsey, on the 7th inst., the police state that the yard of this house is small and close; the inhabitants complain of offensive smells from a long open ditch running on the southeast side of this place. In front of No. 2, Manor-place, Deptford-road, where a death occurred, there is a drain, the smell from which is very offensive, and at the back of the house three very dirty privies, occasioning much annoyance to the inhabitants.

\section{NOVEMBer 11.}

The Metropolis. - The returns from the D, E, H, K, and $T$ divisions of the metropolitan police give 18 new cases and 7 deaths.

With reference to a death that took place at 16 , Redcrosscourt, Borough, the return states that this is the 9 th fatal case in this court, in which there are 13 houses, oceupied by 80 or 90 persons, for the use of whom there are only two filthy privies, the stench from which is very bad, more particularly to persons living opposite them; the drains are also very offensive.

Two new cases and one death are reported as having occurred at the Millbank Prison from the 5th to the 9th instant.

DUNDEE. - Nov. 9,14 deaths.

GoRleston (SUFFoLK). - Nov. 7 to 10, 5 deaths.

DARTFORD. - Nov. 9,3 deaths.

HaRWICH.-Nov, 9, 2 deaths.

\section{November 12}

ARBROATH.-Nov, 10, 1 death.

SoHAM.-Nov. 11,1 death.

LIVERPOoL. -Dr. Duncan, the officer of health of Liverpool, states that since the 24th of October there have occurred in Liverpool 21 cases of cholera and 14 deaths. In five cases the patients were German enigrants, in two inmates of the workhouse, one being a nurse in the cholera wards. The mortality of the town is below the average, and diarrhoa not prevalent. With reference to the ship Guiding Star, he reports, she sailed from the port of Liverpool on the 27th of October with 500 emigrants, and put into Belfast Lough on the 5th of November with loss of spars and sails; arrived in the river last night, having lost 23 of her passengers from cholera between the 30th of October and the 9th of November. The first case (that of an Irish child) occurred after meeting with very stormy weather when three days out at sea. The second case was that of an adult German. A number of the sick, with the remaincler of their families, were landed at Belfast Lough. About 400 have arrived here. The whole were landed to-day, and two who were found suffering from cholera (having been attacked last night) were sent to the hospital. The whole of the remainder, with one exception, were healthy, and seemed to have suffered little from the privations to which they had been exposed. Accommodation was offered to them in the workhouse, but a small proportion only accepted the offer, the remainder going to private lodging-houses. There were about 50 Germans on board, the rest being Irish, English, and Scotch.

ANALYSIS OF THE TYNE WATER AT NEWCASTLE.

A specimen of the Tyne water has been carefully analyzed by Dr. Robert Dundas Thomson, F.R. S.F., Lecturer on Chemistry at St. Thomas's Hospital, a gentleman who had previously paid great attention to the subject of impure water. The following is Dr. Thomson's report:-

\section{"Report on Water taken from the Tyne at Elswick, October' $17 t h$, 1853, two or three hours after low water.}

"The water, when drawn from the jar in which it was conveyed from Newcastle to London, was turbid, from the presence of a considerable quantity of matter, mechanically diffused in the form of flocks throughont the mass of fluid. When the foreign matter was allowed to subside the water presented a brownish aspect, similar to the colour possessed by water which, after a fall of rain, has passed over a soil impregnated with peaty or vegetable substances. On separating the mechanically diffused flocks, which, on agitation have im. parted a muddiness to the water, they were found to consist of organized forms, similar to the appearances presented by infusorial animals, or diatomaceons beings which have been claimed as belonging according to some to the animal, and, according to others, to the vegetable world. These animal or vegetable beings were infested with large numbers of very distinct animalculæ or vibrios, which were sporting about with immense activity, and courting the shade of the living flocky masses. I found the weight of this foreign matter to amount in the gallon to 4.502 grains; of this only 545 grains was matter destructive by heat. The remainder consisted principally of silica, and still retained an organized form, corresponding apparently with the shields of the diatomacere previously mentioned. These possessed a reddish hue from the presence of a minute quantity of oxide of iron, which either entered into the composition of the organized forms, or was derived from a minute portion of sand which may have been diffused through the water. 'The presence of those living forms in water used by the inhabitants of a city it appears to me cannot be viewed as otherwise than highly objectionable in a sanitary point of view, acquainted as we now are with the influence which the lower forms of animal and vegetable life exercise in nature. In addition to these forms presented by the organic matter described, I found no less than $2 \cdot 68$ grains per gallon of vegetable matter dissolved or finely diffused throughout the water, and which was in a condition approximate to that of organization, since it contained a considerable emount of siliceous inorganic matter.

"The total quantity of matter, therefore, observed from organized sources which I found to exist in the water amounted to no less than $7 \cdot 172$ grains per gallon. This must be viewed as a large amount when we take into consideration the fact that the total solid constituents in the gallon were 15.662 grains. The organic matter obtained in the analysis thus approximated to one-half of the foreign ingredients.

"I have also been able to obtain indications of the presence of nitric acid in the water; from which it is rendered probable that human excretions are mingled with the river, a circumstance which I have endeavoured to prore in reference to the well waters of Glasgow, and this renders river water, and still more strongly the well waters sunk in torns, in the highest degree objectionable for domestic use in a sanitary point of view. The time is fast approaching when the inhabitants of cities, warned by an increasing knowledge of the science or health, will no longer consent to be supplied with river watef 